\title{
SLM1 Linkage Map
}

National Cancer Institute

\section{Source}

National Cancer Institute. SLM1 Linkage Map. NCI Thesaurus. Code C70944.

A human linkage map generated from unpublished data from Affymetrix and Dr.

Aravinda Chakravarti's group at Johns Hopkins University, based on genotypes for 2022

microsatellite markers and 6205 SNPs. 